Lozano, Jiménez, José Luis.

Profesor Titular Escuela Arte Granada S.L. Miembro del Grupo de Investigación:

HUM611 Nuevos Materiales para el Arte Contemporáneo.

\title{
Espacios de vigilancia total en el Arte Contemporáneo. El grupo Mediashed.
}

\section{Spaces of total vigilance in Contemporary Art. The Mediashed group.}

TIPO DE TRABAJO:

Comunicación virtual.

PALABRAS CLAVE:

Vídeovigilancia, Arte Contemporáneo, leyes.

KEY WORDS:

Video Surveillance, Contemporary Art, Laws.

RESUMEN.

Con la justificación de convertir la ciudad en un espacio verdaderamente seguro para su ciudadanía, en los últimos años están aumentando las medidas de seguridad en el espacio urbano, un hecho que se viene desarrollando desde hace algunos años pero que nunca se había dado el caso de lugares con tantos sistemas de seguridad. Así con el fortalecimiento de ciertas medidas de seguridad está ocurriendo justo el efecto contrario, estamos asistiendo a la privatización del espacio público, un espacio bajo unas normas, leyes y un control más incidente en la sociedad. Los espacios públicos que permanecían como espacios abiertos, espacios para el individuo que ejercía su estancia libremente, se están convirtiendo en espacios cerrados sometidos cada vez más a control y vigilancia extrema. En el ámbito de la creación artística, están apareciendo en los últimos años una serie de colectivos que dejan en evidencia los sistemas actuales de control y vigilancia, haciendo crítica a los actuales sistemas de vigilancia que hacen que el espectador se sienta cada vez más intimidado ante ellos, este es el caso del grupo MediaShed que proponen una serie de estrategias como reacción a las cámaras de vídeovigilancia y dispositivos de Circuito Cerrado de Televisión (CCTV). Grupo establecido en Inglaterra, MediaShed utilizan los sistemas de vídeovigilancia que controlan el espacio público instalados en las calles, plazas, centros comerciales y que están ahí vigilando continuamente para crear proyectos artísticos como forma de resistencia social y crítica a todos estos equipos tecnológicos que controlan día a día a ser humano, es un espacio abierto a todo el público sin ánimo de lucro, reutilizando sistemas de equipos y tecnología digital, haciendo arte sin coste alguno utilizando el dominio público, en este caso el uso de las cámaras de vídeovigilancia.

\section{ABSTRACT.}

With the justification of making the city a truly safe space for citizenship, security measures in urban space have been increasing in recent years, a fact that has been developing for some years but has never been the case. Places with so many security systems. So with the strengthening of certain security measures is happening just the opposite effect, we are witnessing the privatization of public space, a space under rules, laws and more control in society. Public spaces that remained as open spaces, spaces for the individual who exercised their freedom freely, are becoming closed spaces increasingly subject to extreme control and vigilance. In the field of artistic creation, a series of groups have emerged in recent years that highlight the current systems of control and surveillance, criticizing current surveillance systems that make the viewer feel more and more intimidated by They, this is the case of the group MediaShed that propose a series 
of strategies like reaction to the cameras of video-surveillance and devices of Closed Circuit Television (CCTV). Group established in England, MediaShed use the video surveillance systems that control the public space installed in the streets, squares, shopping centers and that are there continuously watching to create artistic projects as a form of social and critical resistance to all these technological equipment that control day A day to be human, is a space open to all nonprofit public, reusing equipment systems and digital technology, making art at no cost using the public domain, in this case the use of video surveillance cameras.

\section{CONTENIDO.}

\section{INTRODUCCIÓN.}

Según las estadísticas, Inglaterra es el país europeo con más dispositivos de vídeovigilancia por metro cuadrado en las calles de las ciudades y en general en todo el espacio público del país anglosajón, por ejemplo en la actualidad existen más de cinco millones de cámaras que están destinadas a la vídeovigilancia. Por consiguiente, "la sociedad británica es la más vigilada del mundo según un estudio realizado por una agencia del gobierno del Reino Unido, encargada del control de la intimidad de los ciudadanos" ${ }^{1}$.

La vídeovigilancia en ciudades como Londres, se ha visto incrementada en estos últimos años, donde han aumentado ampliamente sus sistemas de control social, durante la última década la ciudad de Londres ha sido testigo del enorme aumento de cámaras de circuito cerrado de televisión, tan solo en la ciudad de Londres hay instaladas en sus calles alrededor de unas cien mil cámaras de vídeovigilancia funcionando en el espacio público ${ }^{2}$. Si bien es cierto, hoy en día no hay registros del gobierno que nos permitan establecer el número exacto de cámaras de vídeovigilancia en el Reino Unido, sí hay cifras sobre la financiación del gobierno central destinado a la instalación de circuitos cerrados de televisión para la vigilancia del espacio público, datos que nos dan una idea de las medidas que está tomando el gobierno y de cómo la vigilancia se está volviendo omnipresente en los espacios públicos de las ciudades anglosajonas. Si observamos los datos sobre esta financiación, entre el año 1994 y 1999, se recaudaron 85 £ millones para la instalación de 580 proyectos de CCTV, $31 \mathrm{f}$ millones de la financiación del Ministerio del Interior y $54 \mathrm{f}$ millones de las Asociaciones. Bajo la iniciativa del Programa de Reducción de Delitos con la instalación de circuitos cerrados de televisión, 153 f millones de los fondos de capital estaban a disposición para la reducción de la delincuencia y de los trastornos de las asociaciones de Inglaterra y Gales ${ }^{3}$. Hay estudios que demuestran cómo la vigilancia es hoy en día en Inglaterra uno de los principales temas de debate. En el caso de la vídeovigilancia en la vía pública, la ciudad cuenta con un dispositivo de CCTV por cada 14 personas aproximadamente, y esto va en aumento, convirtiendo así la ciudad en un espacio de observación total, ningún rincón queda a la sombra de su visualización, cada paso o movimiento en las calles o vía pública, queda grabado y registrado en las bases de datos de la policía, con el único fin de mantener bajo seguridad a sus ciudadanos y asegurarse un ambiente de máxima seguridad en el país.

Pero el verdadero debate está en la efectividad de estos sistemas de control que se están poniendo en evidencia debido a su poca efectividad en la detención de la mayoría de los actos delictivos que se suceden en las calles del país anglosajón, y a posteriori la situación más grave que se da que es la de la vulnerabilidad a los derechos de intimidad del ser humano. Como ejemplo de la poca efectividad que están teniendo las cámaras de vídeovigilancia en los últimos años, durante todo el año 2008, tan sólo se detectaron 5 delitos en el espacio público gracias a estos sistemas de vídeovigilancia ${ }^{4}$.

Si hacemos un repaso a la historia de la ciudad en el año 1993, tras el ataque terrorista del IRA en el Bishopgate, se introdujo en la ciudad una red de cámaras de vídeovigilancia para controlar los accesos a la ciudad de Londres, un hecho que fue conocido como el "anillo de acero". Esta red de cámaras de vídeovigilancia, se han integrado en la ciudad como muchos de los sistemas que hay ya instalados y que operan en los bancos de la ciudad y en las oficinas. Si observamos algunos datos al respecto, el estado parlamentario está monitoreado con una red de 260 cámaras de circuito cerrado de televisión, también el mayor número de comercios de Oxford Street también está cubierto por un circuito de cámaras de seguridad que consta de 35 cámaras que se controlan desde una sala de control centralizado desde la Comisaría de policía de Marylebone. Pero no solo es el centro de Londres el que ha sufrido un incremento del uso de sistemas de circuito cerrado de televisión, Norris y Armstrong (1999) comentan en un relato ficticio de una

\footnotetext{
${ }^{1}$ Diario Clarín.com: "La sociedad británica, la más vigilada del mundo", Último momento, Jueves 2 de noviembre de 2006, Fuente: EFE, [en línea] http://edant.clarin.com/diario/2006/11/02/um/m-01301970.htm. Fecha de consulta: 27-03-2010.

${ }^{2}$ LOBOHEM, F.: Asi nos vigilan. "Echelon"; "Sitel”... El sistema nos espía, Ipunto producciones y ediciones S. L., Madrid, 2010. p. 119. ${ }^{3}$ MCCAHIL, Michael y CLIVE, Norris: CCTV Systems in London. Their Structures and Practices, Urbaneye, Documento de Trabajo $\mathrm{N}{ }^{\circ} 10$, Centro de Criminología y Justicia Penal, Universidad de Hull, Reino Unido, septiembre 2001-febrero 2004. En línea: www.urbaneye.net. p. 2. Fecha de consulta: 19-02-2012.

${ }^{4}$ LOBOHEM, F.: Asi nos vigilan. "Echelon"; “Sitel”... El sistema nos espía, Ipunto producciones y ediciones S. L., Madrid, 2010. p. 119.
} 
historia cotidiana de la videovigilancia, que en un solo día un ciudadano en la ciudad de Londres podría estar siendo "filmado por más de 300 cámaras en más de treinta sistemas de circuito cerrado de televisión independientes" ${ }^{5}$.

Pero como sucedería con las ciudades de Nueva York y Madrid, este aumento de los sistemas de control y vigilancia de la sociedad inglesa, se hizo aún más evidente tras el atentado terrorista que sacudió a la ciudad de Londres en el 7J, unido al miedo que ya existía con anterioridad a robos, actos delictivos que se estaban sucediendo en los últimos años en este país. Fue en este momento, cuando el comportamiento en lo referente a la seguridad y vigilancia del Estado, los gobiernos ingleses comenzaron a blindar sus ciudades en busca de la construcción de un nuevo espacio fortificado mediante la instalación por doquier de una multitud de dispositivos de vídeovigilancia.

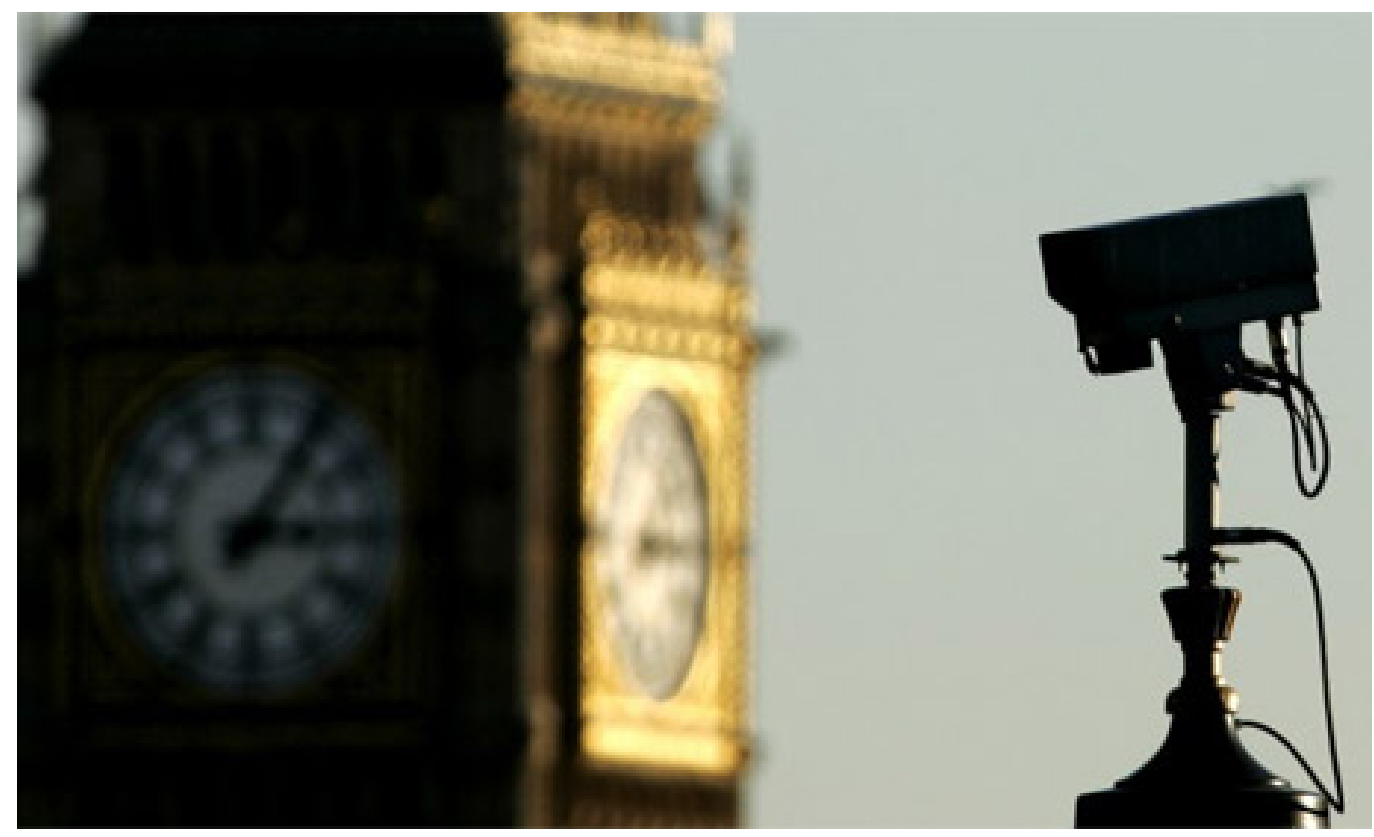

Ilustración 1

En este estado de miedo comenzaron a aparecer nuevos sistemas de vídeovigilancia, en el caso de Inglaterra, se empezaron a instalar cámaras de vídeovigilancia en las calles con sistemas más modernos de vigilancia de grabación, clasificación y almacenamiento, entre ellos cabe destacar los sistemas de vídeovigilancia de reconocimiento facial, capacitados para reconocer de entre la sociedad, ciertos caracteres del individuo que se presenta como sospechoso de haber cometido algún delito o ser miembro de una banda terrorista. Se han estado desarrollando en los últimos años unas cámaras de vídeovigilancia que utilizan un software mediante el cual analiza el comportamiento de las personas que graba la cámara y posteriormente decide qué personas de las que son analizadas son bastante peligrosas y que seguramente puedan cometer cualquier acto delictivo y las que no lo son ${ }^{6}$. Como escribe Lobohem, para explicar estos sistemas de seguridad, "se tratan de cámaras que tratan de predecir acciones delictivas. Es decir, en un autobús por ejemplo, la actividad de las personas de levantarse o sentarse o cualquier otra que ocurra son grabadas y en función del análisis automático de la actividad en base a unos parámetros se envían al centro de control como potencialmente delictivas" ${ }^{7}$. El software que utilizan, registra los rasgos faciales y los compara con las fotografías de los sospechosos que están incluidas en sus bases de datos. Pero han ido apareciendo nuevas formas que han ido dando vida a la vigilancia en la sociedad moderna, como menciona Jacob Israel Bañuelos Capistrán, el "régimen de la vigilancia cobra forma: Circuito Cerrado de Televisión (CCTV), programas de reconocimiento facial, sensores de proximidad, detectores de movimiento, cámaras infrarrojas, cámaras robots, secuenciadores de video, sensores de humo, contactos magnéticos, cámaras de intemperie con radiofrecuencia, cámaras de baja iluminación con cobertura de hasta 120 m. en total oscuridad, de interiores visibles u ocultas, cámaras acuáticas, criptografía, red de inteligencia ECHELON (de Jam Echelon) y ENFOPOL (redes norteamericana y europea respectivamente, dedicadas interceptar y detectar emisiones electrónicas y digitales, conversaciones telefónicas, e-mail y sms, tanto públicas como privadas), espacio Shengen (espacio de vigilancia y seguridad creado

\footnotetext{
${ }^{5}$ McCAHIL, Michael y CLIVE, Norris: CCTV Systems in London. Their Structures and Practices, Urbaneye, Documento de Trabajo $\mathrm{N}^{\circ} 10$, Centro de Criminología y Justicia Penal, Universidad de Hull, Reino Unido, septiembre 2001-febrero 2004. En línea: www.urbaneye.net. p. 2. Fecha de consulta: $19-02-2012$.

${ }_{7}^{6}$ Ibid., p. 119 .

${ }^{7}$ Ibid., p. 119.
} 
para control migratorio e inmigratorio en Europa), CARNIVORE (herramienta de espionaje del FBI)” ${ }^{8}$ Ya no sólo pertenecen al ámbito de la ficción todos estos sistemas de seguridad, sino que en la actualidad están funcionando y controlan nuestras acciones diarias, las últimas tendencias serán la instalación de cámaras de videovigilancia que no sólo graven, sino que también emitirán mensajes a los ciudadanos de lo que no deben de hacer ${ }^{9}$.

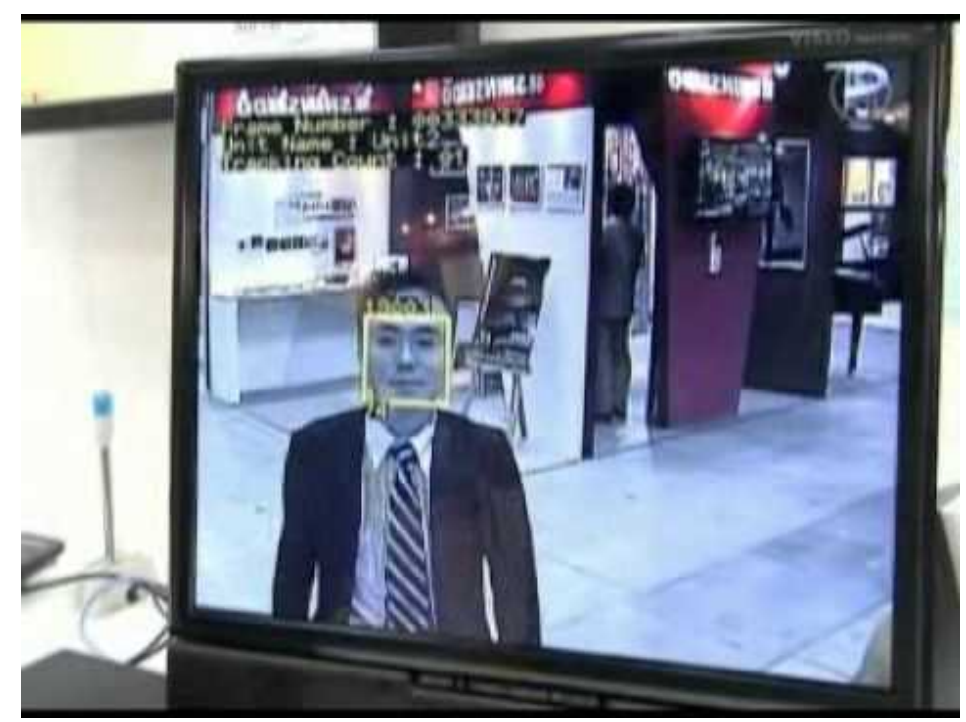

llustración 2

En el caso de Londres podríamos estar hablando del ejemplo más parecido a la distopía que George Orwell describió con 1984, ya que si atendemos a las estadísticas, según cuenta el editor de Defense Tech Noah Shachtman, un ciudadano londinense aparece 300 veces al día de media en una cámara de videovigilancia ${ }^{10}$ será más evidente esta comparación. Cuando se hace referencia al número de cámaras de videovigilancia que hay instaladas en las ciudades inglesas, según los datos Gran Bretaña cuenta ya casi con cuatro millones y medio de cámaras de videovigilancia instaladas, concretamente 4,2 millones de cámaras de circuito cerrado de televisión, convirtiéndose por tanto en una de las ciudades con mayor despliegue de vigilancia en el espacio público del mundo, y como declaró a la BBC, David Murakami-Wood, "Gran Bretaña es el país más vigilado del mundo". Quizá estemos hablando del país con más vigilancia y control del mundo, porque necesitan sentirse seguros, esta sensación de inseguridad en la que viven la sociedad inglesa se justifica por el miedo a posibles atentados, robos, etc., e intentan remediar el miedo y la sensación de inseguridad con la vigilancia extrema, están convencidos que la inseguridad viene reñida por la falta de vigilancia y como bien menciona el Doctor Jacob Israel Bañuelos, "Ia inseguridad es un problema sistémico e integral más que un problema de falta de vigilancia", y continúa, -"la inseguridad no es consecuencia de una falta de vigilancia, tal y como el Estado moderno y contemporáneo argumenta. La inseguridad es consecuencia directa de la desigualdad económica, la miseria y la injusticia social, de la falta de igualdad educativa, la marginalidad territorial y racial, la criminalización de la inmigración y un largo etcétera"11 ${ }^{11}$. Los Gobiernos modernos intentan convencer a la población que la sensación de inseguridad vine remediada con la vigilancia y el control en cualquier contexto de vida cotidiana, de este modo nada queda al margen de la vigilancia y del control. El espacio público poco a poco, sufre una militarización en todas sus facetas, asentando nuevas normas y nuevas conductas que influyen en el comportamiento del individuo. El espacio público se convierte en un espacio de observación, vigilancia y control, todo pasa por un registro de vigilancia, asentando un modelo de sociedad que vive por y para la vigilancia de sus individuos. Pero lo que verdaderamente debe importarnos de la cuestión, como se pregunta Jacob Israel Bañuelos, “¿quién vigila a quién?, ¿quién tiene el poder de vigilar?, ¿quién realiza la vigilancia de la vigilancia?”"12 , ya que en una sociedad en la que la vigilancia ocupa todas sus las facetas hay que prestar especial atención a estas cuestiones con el único fin de evitar la conversión de una sociedad insegura por la falta de seguridad ciudadana por una sociedad vulnerable a cualquier medida de control y vigilancia que pueda atentar contra las libertades y derechos fundamentales del ser humano como el derecho a la propia imagen, al honor y la intimidad y los recogidos en la Declaración de los Derechos Humanos.

\footnotetext{
${ }^{8}$ BAÑUELOS CAPISTRÁN, Jacob Israel: Videovigilancia y seguridad en la era digital, pp. 2-3, [en línea] http://s3.amazonaws.com/lcp/alaic-internet/myfiles/Jacob.pdf. Fecha de consulta: 07-06-2010.

${ }^{9}$ LOBOHEM, F.: Op. Cit., p. 119.

${ }^{10}$ Periódico El Mundo: "Lo que funciona y lo que parece no funcionar. La tecnología y el $7 \mathrm{~J}$ en Londres”, viernes 8 de julio de 2005 , p. 24.

1 Ibid., p. 2.

${ }^{12}$ lbid., p. 2.
} 
Con la intención de conseguir una "seguridad (casi) completa" como dirá José Miguel G. Cortés sometiendo al ser humano a una vigilancia total, se configura el nuevo espacio urbano y la actual sociedad. La situación de control y vigilancia se ha ido agudizando tras los atentados terroristas del 11 de septiembre de 2001 a las Torres Gemelas, tal efecto ha hecho que la sensación de inseguridad aumente considerablemente hasta el punto de que se está configurando un nuevo espacio urbano que centra su interés en el control visual del individuo en un estado de constante vigilancia, en un espacio urbano que se considera libre y que en los últimos años se han ido sacrificando algunos de los derechos fundamentales de una sociedad democrática con la intención de convertirlo en un espacio de máxima seguridad donde cualquier persona pueda sentirse segura. Con la justificación de convertir la ciudad en un espacio verdaderamente seguro para su ciudadanía, en los últimos años están aumentando las medidas de seguridad en el espacio urbano, un hecho que se viene desarrollando desde hace algunos años pero que nunca se había dado el caso de lugares con tantos sistemas de seguridad. Así con el fortalecimiento de ciertas medidas de seguridad está ocurriendo justo el efecto contrario, estamos asistiendo a la privatización del espacio público, un espacio bajo unas normas, leyes y un control más incidente en la sociedad. Los espacios públicos que permanecían como espacios abiertos, espacios para el individuo que ejercía su estancia libremente, se están convirtiendo en espacios cerrados sometidos cada vez más a control y vigilancia extrema. Este es el caso de los Centros Comerciales, destinados al libre uso de las personas como lugares de ocio y tiempo libre, que en la actualidad se han convertido en verdaderos espacios panópticos de observación en los que la cámara de vídeovigilancia adquiere un papel importante en su funcionamiento, como medidas para controlar un posible robo o acto delictivo, espacios sometidos a las nuevas formas de observación y control, pues como dice Paul Virilio, "Las imágenes electrónicas están reemplazando la electrificación de las ciudades y el campo que se creó a finales del siglo XIX y principios del siglo XX. Cámaras automáticas que están sustituyendo las luces de las calles y los neones de las ciudades. De tal modo que cuando uno se mueve en una ciudad moderna, se da cuenta de que todo está concentrado en un monitor de vídeo el cual no es, exactamente, el de la prefectura de la policía o el del control de tráfico, sino, también, el de los supermercados, los circuitos cerrados de televisión en los edificios, etcétera, etcétera"13.

\section{OBJETIVOS}

Desde el análisis de los conceptos de control y vigilancia en la sociedad y toda su implicación a través de la filosofía, la sociología, la política, etc., el principal objetivo que se propone con este trabajo será desarrollar una investigación de una de las propuestas artísticas como es el caso del trabajo del Colectivo MediaShed que se han ido engendrando como consecuencia de la expansión de la vigilancia en los diferentes contextos de la sociedad en los últimos años, a través de un amplio recorrido por el trabajo del colectivo y el caso de alguna de sus propuestas artístico-activistas, preocupados por la problemática de la vigilancia y sus consecuencias entorno a la construcción de la identidad de una sociedad tecnovigilada que nos acontece en la actualidad. Con esta investigación se propone también un estudio sociológico en el contexto de Reino Unido sobre las consecuencias de una sociedad controlada a través de las nuevas tecnologías de la vigilancia que se están desarrollando con la intención de convertirse en herramientas para establecer una mayor seguridad en los diferentes espacios o como medio de mantener bajo un mayor control al individuo y su hábitat que le rodea. Podemos fundamentar el estudio desde el análisis exhaustivo de las políticas de control y vigilancia desarrollas por los propios gobiernos que intentan establecer una serie de normativas que conectan directamente con la mentalidad de una sociedad que intenta "autocontrolarse" en cualquier contexto. El presente trabajo de investigación, por lo tanto, pretende proponer un análisis por el cual podamos entender los estados de la vigilancia desde el punto de vista del artista, contemplando sus preocupaciones, estableciendo una cartografía por aquellas propuestas artísticas realizadas por el colectivo MediaShed donde utilizan la temática del control y la vigilancia como principal preocupación. Esta investigación pretende demostrar que existen obras artísticas que en unos casos reivindican y critican la situación de vigilancia a la que el ser humano es sometido en una sociedad de control, por lo tanto están realizando proyectos artísticos para intentar crear un debate en torno a esta situación de control y vigilancia, a la misma vez, existen otros artistas que plantean proyectos utilizando las mismas herramientas que utiliza la policía, las empresas de seguridad, etc., como es el caso de las cámaras de vigilancia para realizar sus obras, creando una estética estrechamente relacionada con la situación actual como lo es el caso del Colectivo MediaShed. Este artículo es el inicio de una investigación sobre el posicionamiento que presenta el artista ante la situación de control y vigilancia a la que estamos asistiendo en los últimos años y que va en aumento. Esta investigación pretende dar respuesta dentro de la crítica a la sociedad de control y vigilancia y a los sistemas de vigilancia tecnológica a los que estamos sometidos en la vida cotidiana en los diferentes contextos.

\section{DESARROLLO}

En el presente artículo parto de la hipótesis de que existen una serie de artistas que están utilizando las mismas herramientas de control y vigilancia de la sociedad contemporánea para establecer mediante la práctica artística una crítica a la situación de control y vigilancia a la que está siendo sometida la sociedad actual con el aumento de las medidas de seguridad en los diferentes contextos de la sociedad, debido también al gran avance de las nuevas tecnologías para la vigilancia y el control del individuo que hace que la vigilancia penetre más profundamente en la sociedad de manera omnipresente, y por otro lado considerando la situación de inseguridad que hoy en día se ha establecido sobre todo en el espacio público y que tiene connotaciones más notables en una sociedad que se presenta más insegura. Cada artista aborda una estrategia teniendo en consideración la problemática persistente en

\footnotetext{
${ }^{13}$ AAVV, 5 Codes. Architecture, Paranoia and Risk in Times of Terror, Basel, Berlín, Birkhauser, 2006, pp. 126-127.
} 
una sociedad tecnovigilada bajo fuertes medidas de control tecnológico. El espectador, se encuentra frente a esta tipología de proyectos artísticos que implican una confluencia encadenada de pensamientos críticos en su persona a través de los cuales le hacen situarse en su propia realidad cotidiana para desde ahí poder establecer un discurso crítico entre la situación real en la que se encuentra emergente la sociedad actual, el pensamiento crítico del artista representado a través de su proyecto artístico que posee entidad propia, y la posición del espectador como testigo de un acontecimiento real y que va en expansión. Cada artista aborda el tema teniendo en consideración los aportes de una sociedad controlada y vigilada por doquier mediante una serie de cuestiones por las cuales se ha desarrollado una metodología básica y fundamental para la presente investigación. En base a este cuestionamiento habría que preguntarse: ¿el ciudadano está dispuesto a perder su privacidad en el espacio público como pago por su seguridad a través de una vigilancia y un control continuo sobre su persona?, ¿hasta qué punto se encuentra invadida nuestra intimidad con el incesante aumento de dispositivos de vigilancia?. Por otra parte, si aceptamos que la actual sociedad se encuentra controlada y vigilada por una nueva tipología de herramientas de control y vigilancia desarrolladas a través de una nueva oleada tecnológica, una de las preguntas por todo ello se pretende demostrar que los artistas están utilizando las mismas herramientas de control y vigilancia que utiliza la sociedad actual para poder desentramar sus entresijos y en algunos casos desde un posicionamiento crítico poner en entredicho la fiabilidad de esta nueva tipología de sociedad vigilada mediante estos nuevos sistemas de control y vigilancia.

Al igual que en EEUU, y España, en Inglaterra, hay artistas que están preocupados por esta situación de control y vigilancia a la que la sociedad está siendo sometida y por consiguiente este aumento incontrolado de sistemas de control y vigilancia que están apareciendo en la sociedad inglesa, en muchos de los casos, estos artistas hacen una crítica al sometimiento de la población inglesa a las tecnologías de la vigilancia que hoy día conviven y forman parte de las relaciones de poder entre la sociedad. Estos artistas están haciendo uso de los actuales sistemas de control social que están apareciendo hoy en día en las ciudades y que ejercen un control más profundo sobre el ser humano. Hay artistas que están utilizando las mismas herramientas de vigilancia y control que emplean los Gobiernos modernos como sistema de seguridad en los espacios públicos de sus ciudades.

Por lo tanto, encontramos una serie de artistas que están trabajando con dispositivos de videovigilancia como las cámaras de videovigilancia, sistemas de vigilancia de reconocimiento facial, cámaras de infrarrojos y así un largo etcétera. A continuación vamos destacar proyectos de artistas que han reflexionado sobre los nuevos sistemas de control y vigilancia de la sociedad contemporánea, haciendo una crítica a la abundancia en la actualidad de estas herramientas empleadas por los Gobiernos, el Estado, y en definitiva por la sociedad como sistemas de seguridad, utilizando estas mismas herramientas de control y vigilancia para llevar a cabo sus propuestas artísticas.

Entre estos artistas-activistas destacamos al colectivo MediaShed, este colectivo proponen una serie de estrategias como reacción a las cámaras de vídeovigilancia y dispositivos de Circuito Cerrado de Televisión (CCTV), grupo establecido en Inglaterra, MediaShed utilizan los sistemas de vídeovigilancia que controlan el espacio público instalados en las calles, plazas, centros comerciales, y que están ahí vigilando continuamente para crear proyectos artísticos como forma de resistencia social y crítica a todos estos equipos tecnológicos que controlan día a día a ser humano, es un espacio abierto a todo el público sin ánimo de lucro, reutilizando sistemas de equipos y tecnología digital, haciendo arte sin coste alguno utilizando el dominio público, en este caso el uso de las cámaras de vídeovigilancia.

MediaShed ha desarrollado una serie de proyectos como es el caso del llamado "Video Sniffing", que permite realizar vídeo creaciones utilizando como herramienta para grabar estos vídeos los sistemas CCTV del espacio público, cualquier persona puede utilizar este sistema que consiste tan solo en interceptar las señales de las cámaras de vídeovigilancia mediante el uso de la tecnología wireless, utilizando un receptor de señales que se puede comprar en una tienda de electrónica y que tan solo cuesta 30 euros, este sistema puede olfatear en la calle las señales emitidas por las redes inalámbricas de las cámaras de vídeovigilancia, está alimentado con la ayuda de una batería de 12 voltios que acompaña al sistema y una cámara de vídeo que estará conectada que servirá como capturadora de esta señal. El proyecto trata de ir interceptando por la calle señales de las cámaras de vídeovigilancia pudiendo registrar las imágenes que son interceptadas con el funcionamiento de este sistema y así poder dejar al descubierto lo fallos que presentan estos dispositivos en tanto en cuanto que es posible captar sus señales y pinchar sus imágenes. En alguno de los casos es posible realizar alguna acción o performance delante de estos dispositivos de vigilancia en la calle o dentro de cualquier local donde están instalados los dispositivos, este es el caso de "The Duellist", donde MediaShed fueron invitados a participar en marzo de 2007 en "Futuresonic" en Manchester (Inglaterra) como parte del Festival Art for Shopping Centers.

En este vídeo unos profesionales entorno al deporte parkour han realizado una acción que consiste en movimientos acrobáticos saltando obstáculos, utilizando como elementos los objetos que condicionan el propio espacio del Centro Comercial. La película se grabó utilizando tan solo las propias cámaras de vídeovigilancia del Centro Comercial con unas 160 cámaras instaladas, y se grabó durante tres noches, con el espacio vacío de clientes, tan solo la presencia solitaria de dos jóvenes que realizan sus acrobacias libremente en el espacio del Centro Comercial desafiando a la mirada de control que ejercen sobre el espacio las cámaras de seguridad. 
El vídeo, resultado de la grabación de los CCTV del Centro Comercial, se proyectó en una pantalla de plasma de grandes dimensiones dentro del Centro Comercial Arndale en Manchester, un enorme centro comercial que es frecuentado diario por unos 6000 clientes, las imágenes están acompañadas por los propios sonidos que el espacio emite grabados cuando se realizó la acción.

Hay que destacar como el colectivo hace uso de los nuevos medios tecnológicos para el control y la vigilancia de los espacios públicos como una herramienta, eliminando el uso costoso de los medios de grabación, tan solo necesitan piratear estos sistemas de vídeovigilancia de diferentes localizaciones dentro de edificios, centros comerciales o las calles de cualquier ciudad, y realizar una actuación delante de estos sistemas de grabación. De este hecho nace el término "Video Sniffing", que deriva de esta práctica, de "husmear" sobre señales de vídeovigilancia inalámbricas y utilizarlas para controlar su grabación de una manera barata, resultado de ello, aparecen grabaciones directas, controladas, que burlan los sistemas de control de esos espacio, realizando una actuación que pretende ser una crítica directa a la poca fiabilidad y seguridad que presentan hoy día algunos sistemas de control para los espacios públicos y privados.

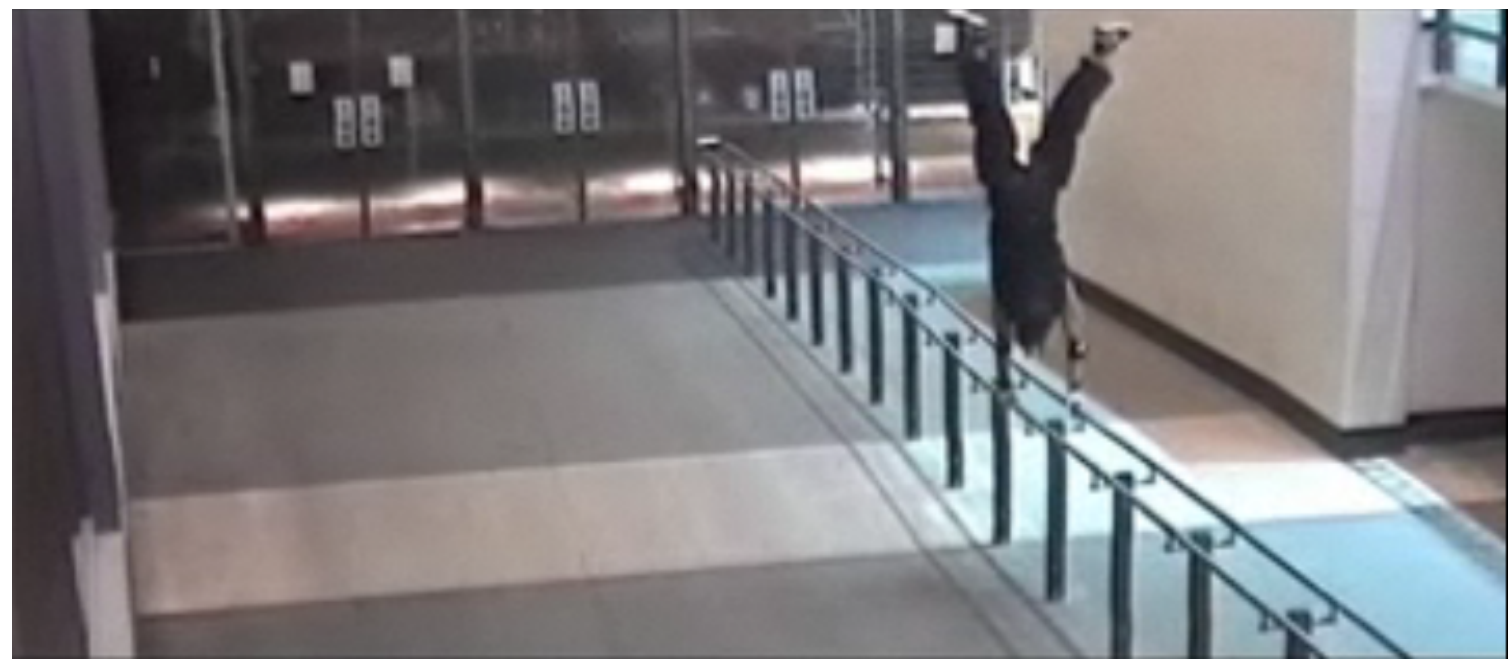

Ilustración 3

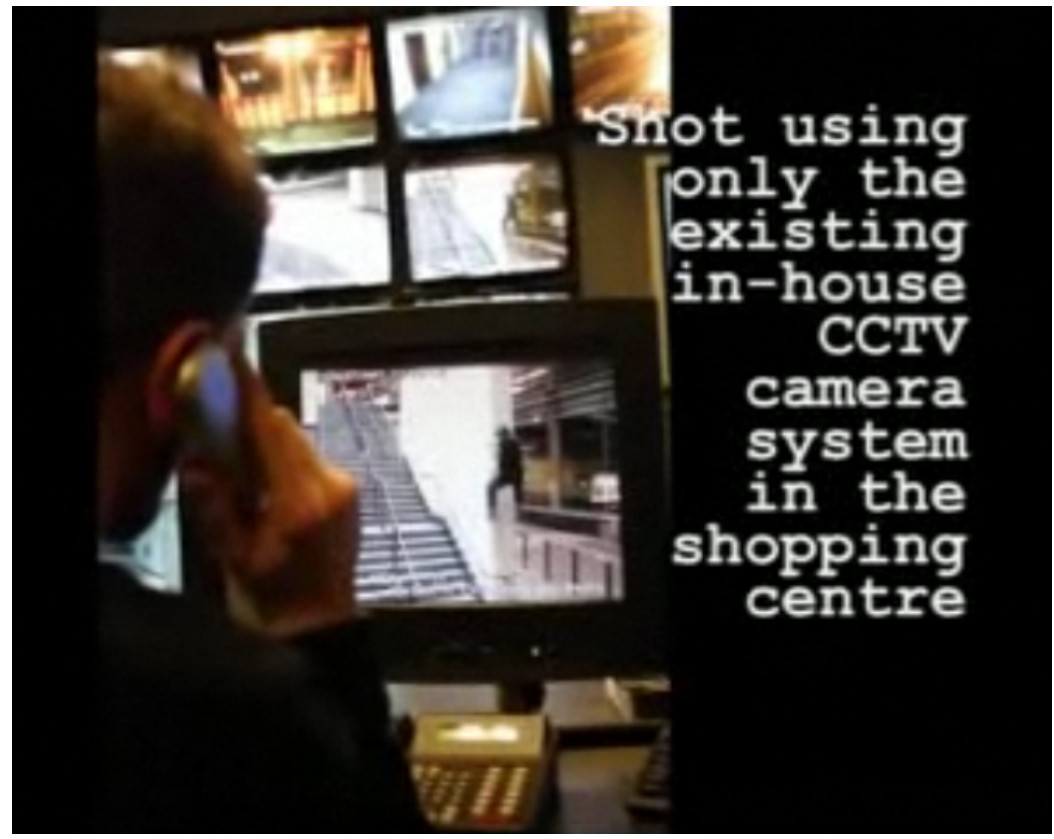

Ilustración 4 
El colectivo invita a sus miembros y también al público en general en su página web http://mediashed.org, a participar en la propuesta. Cualquier persona puede participar libremente en esta práctica de video sniffing, puede realizar estos vídeos, tan solo será necesario comprar este dispositivo antes mencionado que detecta, intercepta señales y graba las imágenes resultado de la grabación que captan estos dispositivos de vídeovigilancia. Este trabajo como destacará uno de los integrantes del Colectivo Graham Harwood en el Simposio Goodbye Privacy ars electronic, "MediaShedes un espacio de "medios libres" abierto al público en el este de Inglaterra. Los medios de comunicación son gratuitos -como la libertad de expresión, la cerveza no es gratis- son un medio de hacer arte, hacer cosas o simplemente decir lo que quieres por poco o ningún costo financiero usando el dominio público, software libre $y$ equipo reciclado. También se trata de decir lo que quieres "libremente", utilizando medios accesibles que pueden ser separados y reutilizados sin restricciones y controles innecesarios" ${ }^{14}$. Se trata de involucrar a cualquier persona en el proyecto, no solo a artistas, colectivos de activistas o hackers, para hacerles ver de los fallos que presentan hoy día estos sistemas de control y como cualquier persona pude acceder libremente a estas herramientas de vídeovigilancia con un sistema tecnológico muy sencillo que cualquier persona puede adquirir libremente en una tienda. Uno de los ejemplos de participación pública se llevó a cabo con un grupo de niños que participaron en la propuesta. El colectivo MediaShed involucró a un grupo de niños en el proyecto y ellos mismo compraron estos dispositivos baratos para grabar sus vídeos utilizando estas cámaras de vídeovigilancia inalámbricas. No era necesario hacer uso de otras cámaras de vídeo habiendo tantas cámaras en el espacio público libremente y con fácil acceso. Estos jóvenes iban interceptando por las calles las señales de estas cámaras de vídeovigilancia inalámbricas y realizando delante de ellas sus actuaciones. Resultado de ello lo podemos observar en la instantánea de la llustración 3.

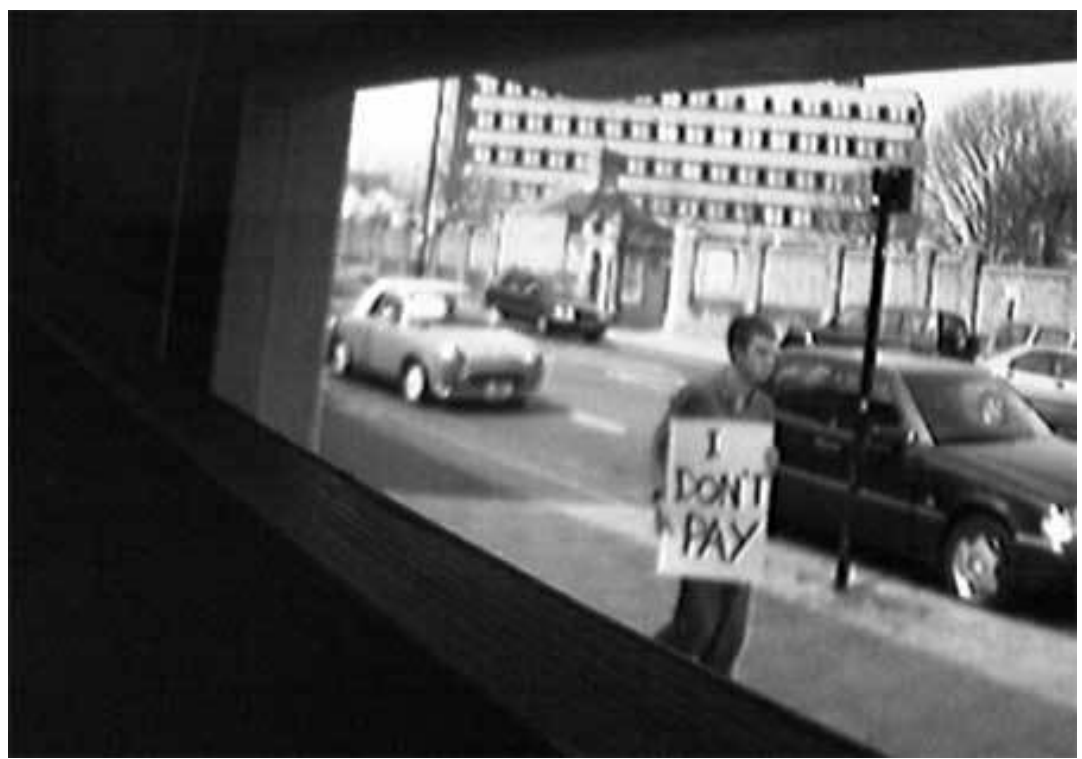

Ilustración 5

\section{CONCLUSIÓN.}

Como resultado del trabajo que realizó el colectivo MediaShed con el uso y acceso libre a los sistemas CCTV de vigilancia para hacer cine o vídeo creaciones, nace en Reino Unido GEARBOX, http://gearbox.mediashed.org/es ${ }^{15}$. GEARBOX es un conjunto de herramientas de vídeo de uso libre desarrollado por el colectivo MediaShed y Eyebeam Studios en Nueva York. En esta aplicación se le explica paso a paso al público que accede a ella cómo grabar imágenes utilizando diferentes combinaciones y recursos de cámaras de vídeovigilancia de forma gratuita y de fácil acceso para realizar estos "Video Sniffing”, enseñan también como utilizar recursos baratos de cámaras de vídeovigilancia que están colgadas en puntos estratégicos, para hacer simular por ejemplo una cámara aérea, pero también enseñan al público como crear vídeos profesionales con técnicas muy profesionales utilizando métodos de bajo presupuesto, para grabar películas con estos sistemas CCTV y no tener que gastar nada de dinero. Como puede comprobarse a la luz de lo expuesto en el presente artículo, se analiza la problemática de la vigilancia desde el trabajo artístico del colectivo activista MediaShed,

\footnotetext{
${ }^{14}$ Ver la web: http://we-make-money-not-art.com/in_linz_several/

${ }^{15}$ Ver la web: http://gearbox.mediashed.org/es
} 
analizando en primer lugar las diversas políticas de control y vigilancia que existen en la sociedad inglesa, haciendo un amplio análisis por los diferentes modelos y herramientas de vigilancia que son hoy en día aplicados a la sociedad como herramientas para el control de sus habitantes. El objeto de estudio es abarcado dentro de tres estados importantes para el buen entendimiento de la presente investigación, por un lado, se pretende demostrar la inquietud y preocupación de algunos artistas por la situación desbordada de control y vigilancia que se ha instaurado en los últimos años ante la amenaza de diversos acontecimientos sucedidos progresivamente sobre todo en Occidente, y más concretamente en Inglaterra. Todo ello magnificado desde el punto de vista tecnológico, que ha producido un cambio significativo en lo que se refiere al control y vigilancia. Esto tiene su reflejo en la aparición incesante de nuevas herramientas de control y vigilancia tecnológica a partir de los años 60, por la cual el artista está haciendo uso de estos sistemas de vídeovigilancia, como en el caso de las cámaras de vigilancia, las de reconocimiento facial, etc., estos colectivos de artistas están desarrollando una serie de propuestas artísticas que sirven de detonador en muchos casos desentramando así la potencialidad de la vigilancia sobre la sociedad actual y aclarando sus consecuencia que han ido en detrimento de sus habitantes. Por todo ello, el colectivo MediaShed, está utilizando las mismas herramientas que utiliza la policía en el control del espacio público o el Estado en la vigilancia en las ciudades para establecer un clima de máxima seguridad con la presencia de este tipo de dispositivos que convierten las ciudades en un espacio fortificado. El presente artículo también da respuesta a las preocupaciones del artista sobre la situación de vigilancia y control a la que se somete a la sociedad en los diferentes contextos, desarrollando una serie de proyectos como "The Duellist", que presentan un posicionamiento crítico ante esta situación de vigilancia desde una perspectiva video-activista mostrando las fragilidad de los actuales sistemas de control y vigilancia que inundan hoy en día los espacios públicos por los que transitamos.

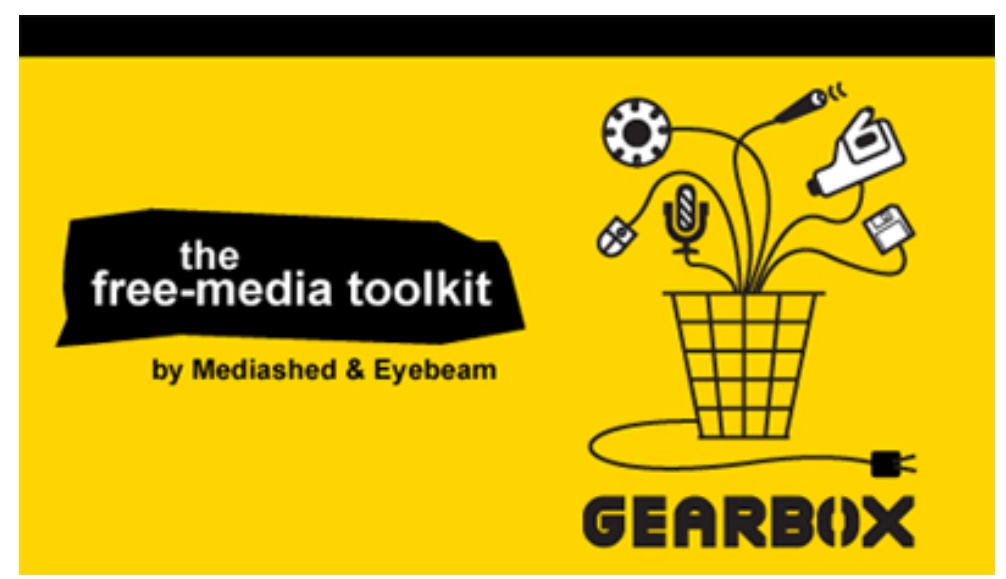

llustración 6

\section{FUENTES REFERENCIALES.}

AAVV, 5 Codes. Architecture, Paranoia and Risk in Times of Terror, Basel, Berlín, Birkhauser, 2006, pp. 126-127.

BAÑUELOS CAPISTRÁN, Jacob Israel: Videovigilancia y seguridad en la era digital, pp. 2-3, [en línea]

http://s3.amazonaws.com/lcp/alaic-internet/myfiles/Jacob.pdf.

CORTÉS, José Miguel G.: La ciudad cautiva: Control y vigilancia en el espacio urbano. Ediciones Akal. Barcelona. 2010.

LOBOHEM, F.: Así nos vigilan. "Echelon"; "Sitel"... El sistema nos espía, Ipunto producciones y ediciones S. L., Madrid, 2010.

MCCAHIL, Michael y CLIVE, Norris: CCTV Systems in London. Their Structures and Practices, Urbaneye, Documento de Trabajo N 10, Centro de Criminología y Justicia Penal, Universidad de Hull, Reino Unido, septiembre 2001-febrero 2004. En línea:

www.urbaneye.net. p. 2.

REISZ, Carlos F.: MANUAL DE TECNOLOGÍA PROFESIONAL EN CCTV, Edición del autor. 2a edición, 2002.

VIRILO, Paul: La máquina de la visión. Cátedra. Madrid, 1975.

WHITAKER, R.: El fin de la privacidad: como la vigilancia total se está convirtiendo en realidad. Paidos Ibérica. Barcelona, 1999. 